\title{
The Effect of Ethanol Psidium guava Leaf Extract on Blood Pressure in Normotensive Guinea Pigs
}

\author{
Abayneh Elias ${ }^{1}$, Daniel Seifu ${ }^{2}$, Frank Ashall ${ }^{2}$, Tesfaye Tolessa ${ }^{3}$ \\ ${ }^{1}$ Department of Biological Sciences, Dire Dawa University, Dire Dawa, Ethiopia \\ ${ }^{2}$ Department of Medical Biochemistry School of Medicine, College of Health Sciences, Addis Ababa University, Addis Ababa, Ethiopia \\ ${ }^{3}$ Department of Medical Physiology, School of Medicine, College of Health Sciences, Addis Ababa University, Addis Ababa, Ethiopia
}

Email address:

abicho.elias6@gmail.com (A. Elias),daniel.seifu@aau.edu.et (D. Seifu), frankashall@yahoo.com (F. Ashall), tesfayet2002@yahoo.com (T. Tolessa)

\section{To cite this article:}

Abayneh Elias, Daniel Seifu, Frank Ashall, Tesfaye Tolessa. The Effect of Ethanol Psidium guava Leaf Extract on Blood Pressure in Normotensive Guinea Pigs. American Journal of Biomedical and Life Sciences. Vol. 5, No. 3, 2017, pp. 47-53. doi: $10.11648 /$ j.ajbls.20170503.12

Received: April 18, 2017; Accepted: May 2, 2017; Published: June 20, 2017

\begin{abstract}
Non-communicable diseases are severe world health problems mainly in sab Saharan- African countries developing countries including Ethiopia. Cardiovascular diseases are one of the major non-communicable diseases increase with rises of hypertension. Hypertension is elevation of systolic blood pressure greater than or equal to $140 \mathrm{~mm} \mathrm{Hg}$ and/or diastolic blood pressure greater than or equal to $90 \mathrm{~mm} \mathrm{Hg}$. A billion people affected globally and millions of them deaths annually. It is significant risk factor for cardiovascular disorders. Some medicinal plants are traditionally used for treatments hypertension. Psidium guava is one popular medicinal plant which is widely used in traditional medicine treatment of different diseases such as diabetes, vomiting, diarrhea and dyslipidemia. The study was designed to identify the effect of P. guava leaf extract on hypertension in guinea pigs. The study was conducted on eight male guinea pigs to measure the effect of ethanol P. guava leaf extract by using invasive methods. The result was analyzed by using independent student $t$ test and one way ANOVA. Ethanol extract of $P$. guava leaf showed a significant $(\mathrm{p}=0.05, \mathrm{p}=0.001)$ reduction of blood pressure of in normotensive guinea pigs in dose dependent manner. The effect of $P$. guava leaf extract in reduction of blood pressure is may be due to a number of phytochemical contents.
\end{abstract}

Keywords: Blood Pressure, Cardiovascular Diseases, Extract, Effect, Guinea Pigs, Hypertension, Normotensive, Psidium guava

\section{Introduction}

Hypertension is elevation of blood pressure greater than or equal to $140 / 90 \mathrm{~mm} \mathrm{Hg}$ [1]. There are many consequences of hypertension. An increase in its prevalence leads to dramatic rises in the incidence of cardiovascular diseases (CVDs) worldwide mainly in sub-Saharan Africa and its burden is increasing from time to time $[2,3]$. Different factors can promote hypertension such as gender, diabetes, chronic kidney disorders, age, genetic factors, alcohol consumption, dyslipidemia, and smoking and so on $[4,5,6]$. It can be primary which resulted from sedentary lifestyle and diet which accounts for 90 to $95 \%$ and secondary resulted from chronic kidney disorders which accounts for 5 to $10 \%[7,8$,
9]. Dysfunction of arterial sub-endothelial cells, increased activity of the renin-angiotensin-aldosterone system, central nervous system dysfunction are major defects in biochemical pathways in which hypertension can be developed [10]. There are many different types of drugs such as angiotensin converting enzyme inhibitors, (ACE), angiotensin receptor blockers (ARBs), alpha and beta blockers, calcium channel blockers (CCBs) [11]. Almost all of these drugs have their own side effects on human health.

Cheapness, less toxicity and easily available of many medicinal plants, make them as potential sources of medicines for different types of diseases worldwide. This is mainly may be due to having of many phytochemical ingredients that can attack different types of microorganisms, scavenge reactive oxygen species and develops different 
drugs. About three-fourth of the world population relies on plants' products for their health care [12]. Above $80 \%$ of the Ethiopian population depends on plants for their traditional medicine for their healthcare [13]. Many hundreds of plants have been using traditionally as a medicine for different ailments. Plants can induce relaxation of vascular smooth muscle by various mechanisms such as potassium channel opening, calcium channel blocking, stimulating nitric oxide activities and receptor antagonism [14]. This is might be due to their richness of them with different phytochemicals. Annona and Garlic were reported to lower an elevated blood pressure by stimulating nitric oxide production, results vasodilatation [15]. As reported [16], Mangifera indica induced blood pressure reduction by balancing electrolytes. As studied by [17], Anona muricata leaves aqueous leaf extract showed decreased blood pressure in normotensive Sprague Dawley rats through peripheral mechanisms involving the antagonism of $\mathrm{Ca}^{2+}$. Report done by $[14,18]$, showed antihypertensive uses of fruit of lemongrass and chayote. According to the investigation by [19], Parinari curatellifolia locally is used in treating hypertension in South Western Part of Nigeria. As reported by [20] on efficacy and mechanisms of quercetin in treatment of hypertension, shown vasorelaxation of isolated aortas of rats, by inhibiting the action of endothelin-1 (ET-1) at the gene transcription level, and promoted the production and action of nitric oxide on endothelium cells. According to study done on bioavailability of dietary polyphenols, quercetin improved endothelial functions through inhibiting endothelial ET-1 production and promoting nitric oxide production and bioavailability [21].

Psidium guava (P. guava) is a small medicinal tree. Mexico, Central America, and northern South America were its origin. Its family is Myrtaceae. It has been traditionally used as a medicinal plant many parts of the world for a number of ailments [22]. The red (P. guajava var. pomifera) and the white (P. guajava var. pyrifera) are major varieties of $P$. guava [22]. It contains numerous vitamins, antioxidants, polyphenolic and flavonoids can prevent CVDs [23]. As stated in many animals' studies by different researchers, $P$. guava leaves, fruit, roots, or branches had potential medicinal effects [23, 24]. There are no published studies of the medicinal effects of $P$. guava in Ethiopia. Even though there are no published medicinal effects of $P$. guava in Ethiopia, traditionally humans use it to protect different diseases such as nausea, vomiting, diarrhea and others. It also can be used as an antimicrobial and antibacterial anti-inflammatory agent [25]. As reported in different researches from animal and human studies. Different parts of this plant uses for diabetes and dyslipidemia [24, 26]. As suggested on different animal studies $P$. guava may have strong hepato-protective benefits, anti-oxidant and anti-cancer properties [27, 28]. Several studies shown anti-diarrheal and antimicrobial activity effects of $P$. guava [29, 30]. However, some studies showed negative effects of $P$. guava have been described; for example impaired spermatogenesis in rats [31]. The effects of $P$. guava may be due to the presence of many different phytochemical compounds such as vitamin $\mathrm{C}$, vitamin $\mathrm{A}$, iron, calcium, manganese, phosphoric, oxalic and malic acids, saponin combined with oleanolic and others. Lycopene, quercetin, $\alpha$-pinene, $\beta$-pinene, limonene, menthol are compounds from its polyphenols, resin, gallic acid, tannin, phenolics, and flavonoids are found in different parts of this medicinal plants [8, 32]. Mainly this study was designed to examine the effect of an ethanol $P$. guava leaf extract on blood pressure in normotensive guinea pigs.

\section{Material and Methods}

The in vivo experiment was carried out according to methods described previously [33]. Six male guinea pigs (300 $-600 \mathrm{~g}$ ) were anaesthetized intraperitoneal with pentobarbital (60 mg/kg, i.p.). The trachea was exposed using a scalpel blade and cannulated, and the guinea pigs were artificially ventilated (Bioscience, 815-51190-1, Sheemess, Kent, UK). The right carotid artery was cannulated with a heparinized saline-filled catheter attached to a pressure transducer (BBC, Goez, Metrawatt, Model SE 120) for continuous recording of blood pressure. Different cumulative doses (12, 26, 42, 60 and $80 \mathrm{mg} / \mathrm{kg}$ ) of ethanol extracted $P$. guava leaf were injected intravenously (via right external jugular vein) followed by a saline flush $(0.2 \mathrm{~mL})$. After each treatment with leaf extract, blood pressure was allowed to return to baseline prior to treatment with the next dose of extract. Blood pressure was continuously monitored via a transducer connected to the left carotid artery. Pulse pressure was obtained by subtracting diastolic blood pressure (DBP) from systolic blood pressure (SBP), and mean arterial blood pressure (MABP) was also determined from the sum of DBP plus one-third of pulse pressure. All readings were expressed as the mean \pm standard error of the means. Comparison was done with paired t-test and ANOVA, $\mathrm{p}<0.05$ was considered significant.

\section{Results}

The effect of ethanol extract of $P$. guava leaf on blood pressure in guinea pigs before and after treatment with various doses of $(12,26,42,60$ and $80 \mathrm{mg} / \mathrm{kg})$ injection through the right jugular vein was examined. The blood pressure was continuously monitored via a transducer connected to the left carotid artery. The mean systolic blood pressure (SBP) was reduced from $84.52 \pm 0.94 \mathrm{mmHg}$ to $77.50 \pm 1.84 \mathrm{mmHg}$ when the guinea pigs were treated with dose of $12 \mathrm{mg} / \mathrm{kg}$ and from $84.52 \pm 0.94 \mathrm{mmHg}$ to $69 \pm$ $2.24 \mathrm{mmHg}$ when guinea pigs were treated with $80 \mathrm{mg} / \mathrm{kg}$ leaf extract (Figure 1). The mean diastolic blood pressure (DBP) of guinea pigs treated with each dose of leaf extract were significantly $(\mathrm{p}=0.05, \mathrm{P}=0.001)$ decreased than $\mathrm{DBP}$ guinea pigs before treatment (Figure 2). Mean DBP of guinea pigs before treatment was $62.67 \pm 1.20 \mathrm{~mm} \mathrm{Hg}$, whereas treatment with $12 \mathrm{mg} / \mathrm{kg}$ extract lowered DBP to a mean of $56.17 \pm 1.78 \mathrm{mmHg}$, and treatment with increasing doses of extract caused progressively higher drops in DBP, showing a dose-dependent effect (Figure 2), as seen with the effect of extract on systolic blood pressure. Thus, $80 \mathrm{mg} / \mathrm{kg}$ leaf 
extract caused a drop in DBP from $62.67 \pm 1.20 \mathrm{~mm} \mathrm{Hg}$ to $45.33 \pm 1.48 \mathrm{mmHg}$. And the pulse pressure was calculated as (SBP-DBP) were no significant differences $(p=0.526)$ between pulse pressure before and after treatment of guinea pigs with ethanol extract of $P$. guava leaf at all doses (Figure 3). The Mean Arterial Blood Pressure in guinea pigs calculated as $\mathrm{DBP}+\frac{1}{3}(S B P-D B P) \quad$ or $D B P+$ $\frac{1}{3}$ (pulsepressure) was significantly reduced $(\mathrm{p}=0.05$, $\mathrm{P}=0.001$ ) in guinea pigs treated with ethanol $P$. guava leaf extract in dose dependent manner as compared with guinea pigs before treatment (Figure 4).

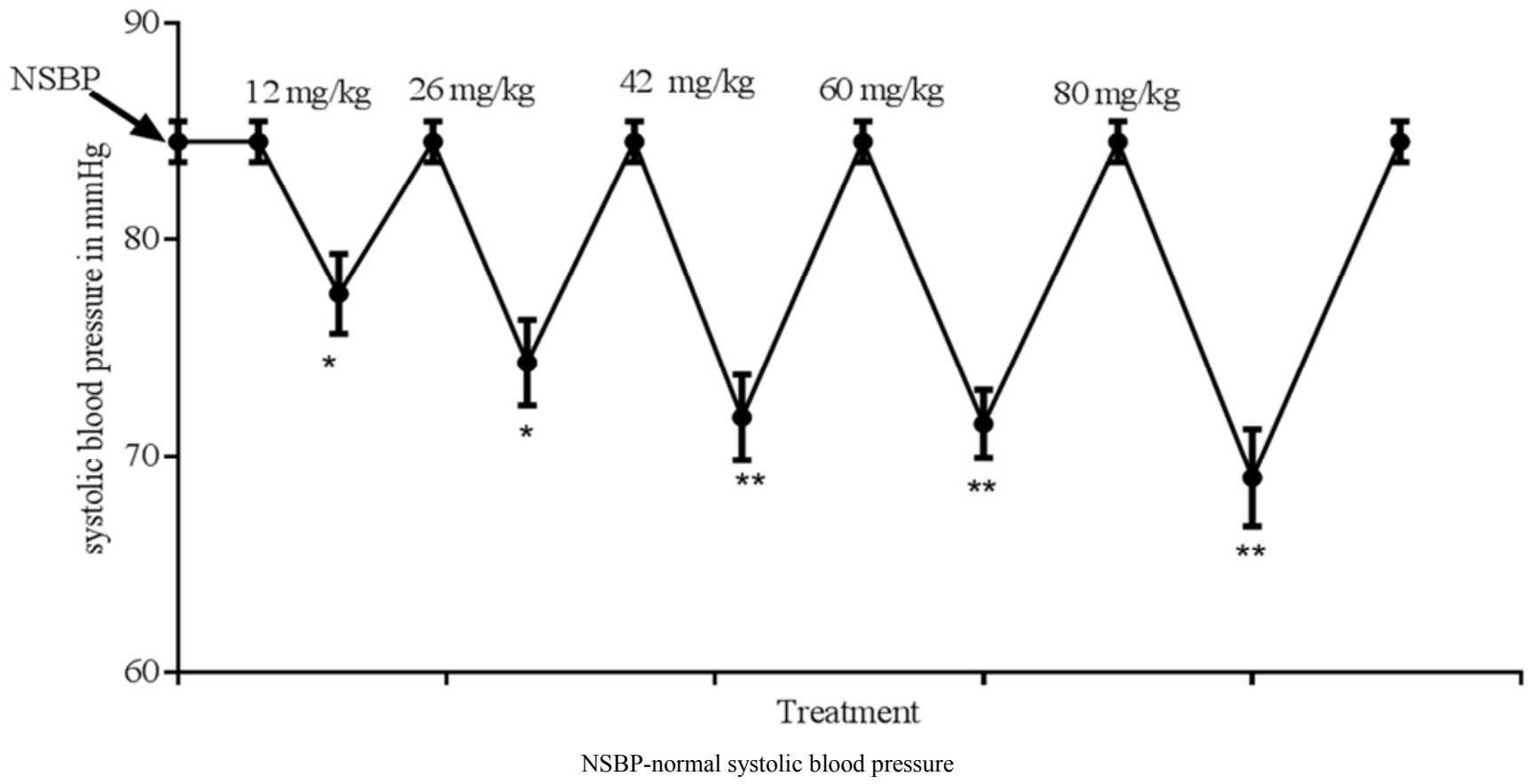

Figure 1. Effect of P. guava leaf extract on systolic blood pressure of guinea pigs.

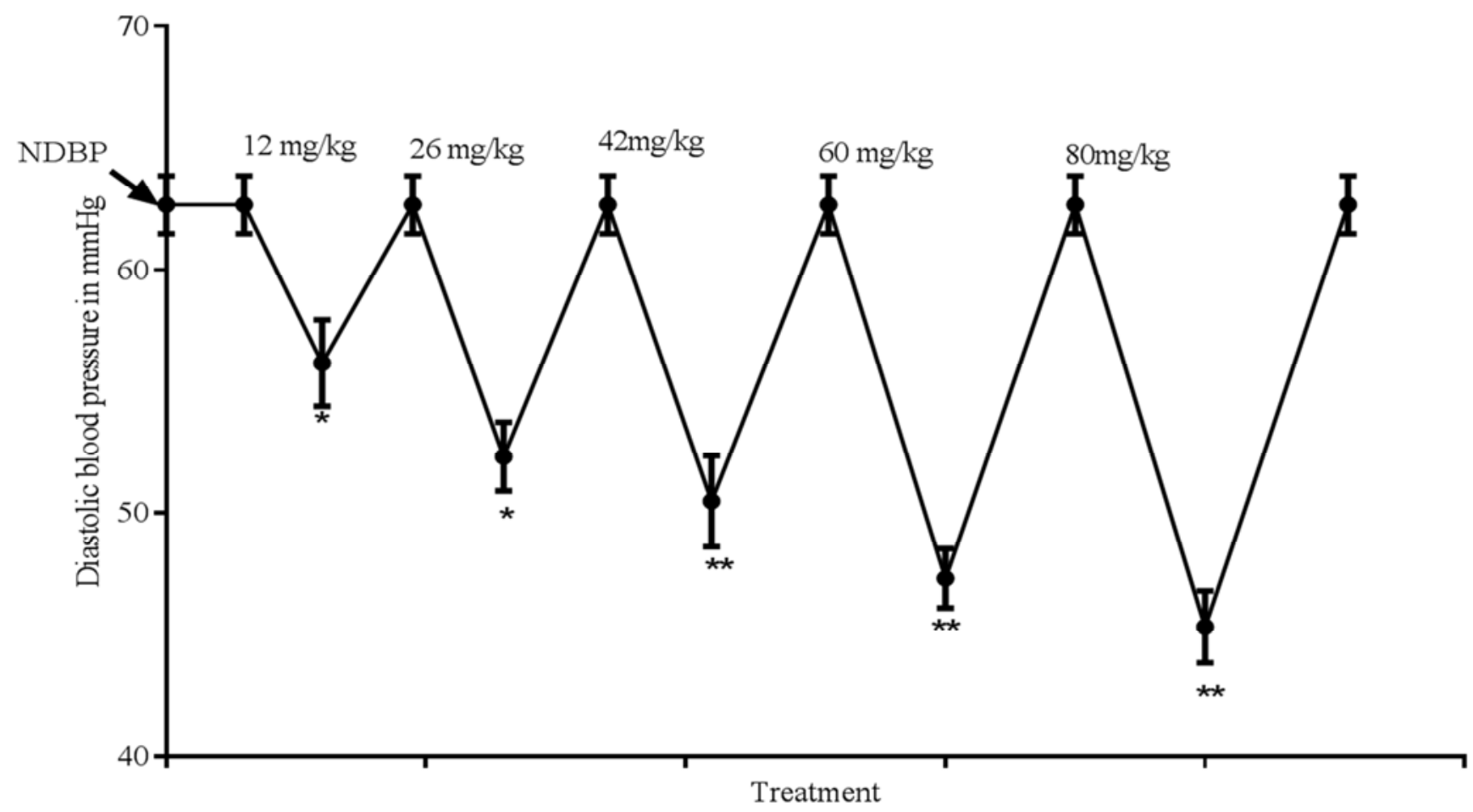

NDBP- normal diastolic blood pressure

Figure 2. Effect of ethanol extract of P. guava leaf on diastolic blood pressure of guinea pigs. 


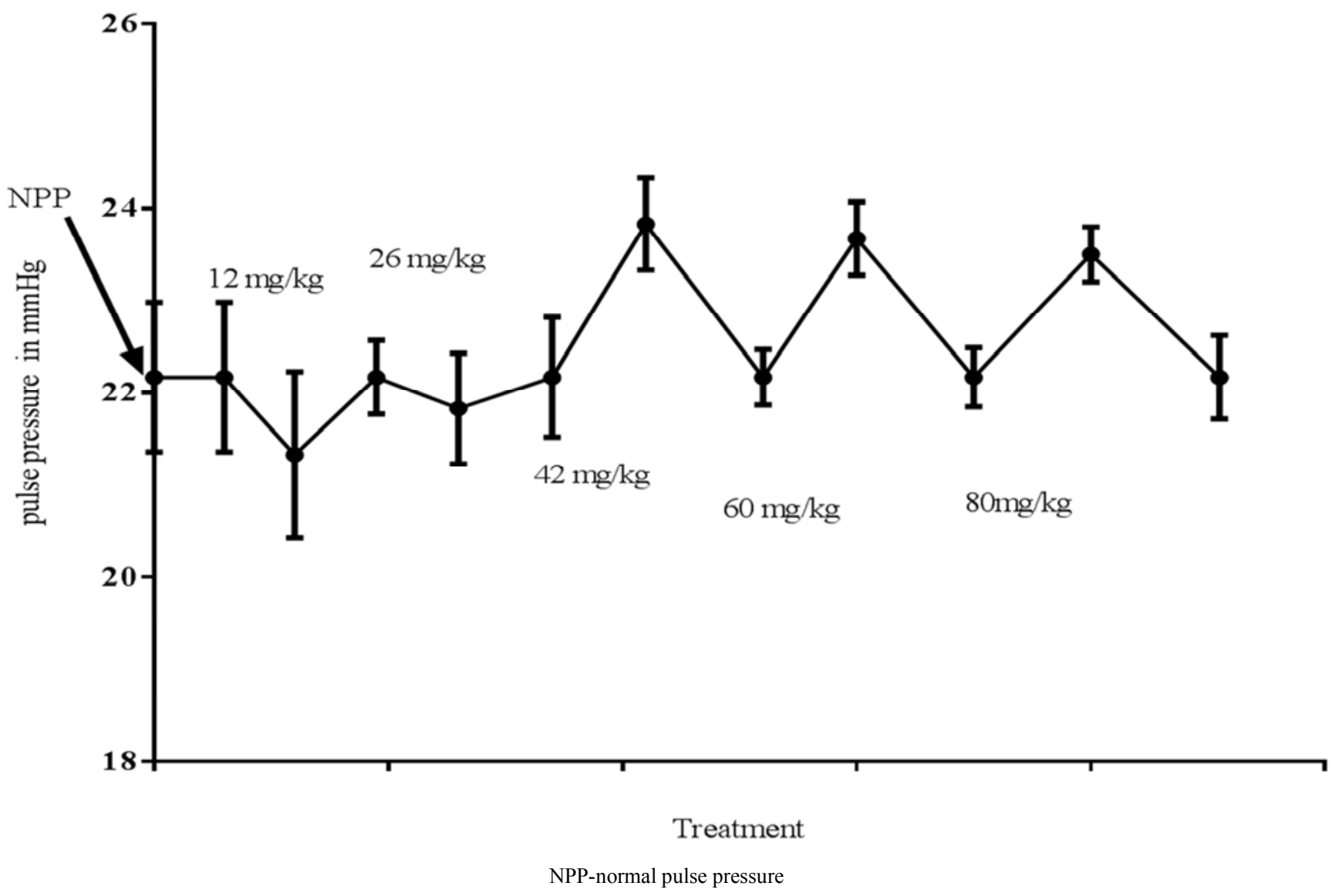

Figure 3. Effect of ethanol extract of P. guava leaf on pulse pressure (SBP-DBP) in guinea pigs.

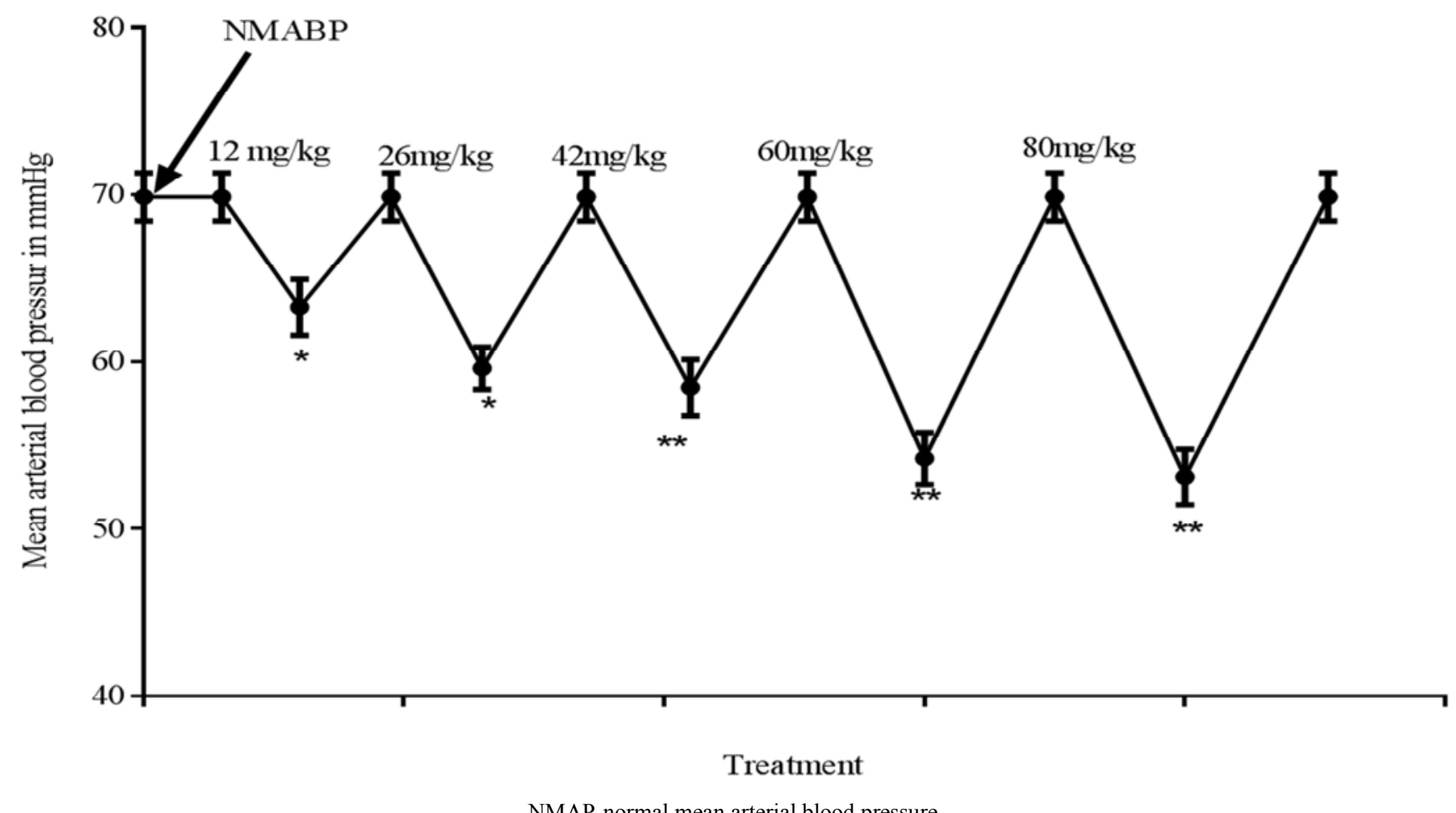

NMAP-normal mean arterial blood pressure

Figure 4. Effect of ethanol extract of P. guava leaf on mean arterial blood pressure in guinea pigs. 


\section{Discussions}

Hypertension is elevation of blood pressure greater than or equal to $140 / 90 \mathrm{~mm} \mathrm{Hg}[1]$. It is worldwide health and economic problem affects many peoples. Its prevalence is different depending on explosion to risk factors in addition to genetic factors, age, gender and etc. For instance one $50 \%$ of dyslipidemia patients can be caused by hypertension in American adults $[3,6]$. It is major cardiovascular risk factors and their prevalence is increasing worldwide [8]. This is true for sub-Saharan Africa countries including Ethiopia [3, 25].

As reported by [12], about three-fourth of the world population relies on plants' products for their health care. This is due to ease of accessibility and cheapness of the plants. Medicinal plants contain many compounds which are active in protecting different diseases. These products act individually, synergistically, and they may also act synergistically with synthetic pharmaceuticals. Out of many medicinal plants, $P$. guava is reported as protective agent for different diseases. In Ethiopia, there are no major published studies of the effects of $P$. guava on except on anti-microbial and anti-inflammatory effect on rats [30].

Both systolic and diastolic blood pressure of normal guinea pigs was reduced $(\mathrm{p}=0.05, \mathrm{p}=0.001)$ in when guinea pigs were intravenously treated with ethanol extract of $P$. guava leaf (Figures 1 and 2). The reduction of blood pressure in normotensive guinea pigs was might be due to different phytochemical compounds. Similarly study done by $[8,32]$ phytochemicals such as lycopene and quercetin have potential to induce vasodilation by stimulating production of nitric oxide that can cause relaxation of smooth blood vessels. Another study also described that on aqueous leaf extract of Anona muricata showed that there was decreased blood pressure in normotensive Sprague Dawley rats [17]. This is might be by the mechanisms of antagonism of $\mathrm{Ca}^{2+}$ which results vasodilation of blood vessels. Similarly researches done $[14,18]$ on fruits of lemongrass and chayote showed antihypertensive effect.

The calculated pulse pressure as (SBP-DBP) was nearly unchanged in ethanol extract leaf of $P$. guava treated normotensive guinea pigs as observed in (Figure 3). This is due to almost equal reduction in systolic and diastolic pressure as a result of treatment of normotensive guinea pigs when treated by the extract. Because pulse pressure was calculated from systolic and diastolic blood pressure of normotensive guinea pigs after the treatment by extract. Though it is not statistically significant $(\mathrm{p}=0.526)$ change, there seemed to be a possible trend towards a differential effect on systolic or diastolic blood pressure at concentrations above $42 \mathrm{mg} / \mathrm{kg}$. The calculated mean arterial blood pressure $\mathrm{DBP}+\frac{1}{3}(S B P-D B P)$ or $D B P+\frac{1}{3}$ (pulsepressure) was significantly reduced $(\mathrm{p}=0.05, \mathrm{p}=0.001)$ as compared to normal blood pressure of guinea pigs. This because there were high reductions $(\mathrm{p}=0.05, \mathrm{p}=0.001)$ in diastolic blood resulted from treatment of guinea pigs with extract.

The mean systolic blood pressure was reduced from 84.52 $\pm 0.94 \mathrm{mmHg}$ to $77.50 \pm 1.84 \mathrm{mmHg}$ significantly reduced $(\mathrm{p}=0.05)$ when guinea pigs were treated with the dose of 12 $\mathrm{mg} / \mathrm{kg}$ extract whereas from $84.52 \pm 0.94 \mathrm{mmHg}$ to $69 \pm$ $2.24 \mathrm{~mm} \mathrm{Hg}$ significantly reduced $(\mathrm{p}=0.001)$ when guinea pigs were treated with the dose of $80 \mathrm{mg} / \mathrm{kg}$ extract as indicated in figure 1. Similarly mean diastolic blood pressure of guinea pigs after treatment by the extract of $12 \mathrm{mg} / \mathrm{kg}$ was $62.67 \pm 1.20 \mathrm{~mm} \mathrm{Hg}$ to $56.17 \pm 1.78 \mathrm{mmHg}$ which is significantly reduced $(\mathrm{p}=0.05)$ as comparted to normal blood pressure of guinea pigs. And diastolic blood pressure was reduced from $62.67 \pm 1.20 \mathrm{~mm} \mathrm{Hg}$ to $45.33 \pm 1.48 \mathrm{mmHg}$ when guinea pigs were treated with dose of $80 \mathrm{mg} / \mathrm{kg}$ leaf extract resulted significant reduction $(\mathrm{p}=0.001)$ in diastolic blood pressure of guinea pigs as compared to diastolic blood pressure of normal guinea pigs figure 2. These results indicated $P$. guava leaf extract reduces systolic and diastolic blood pressure in guinea pigs in dose dependent manner. This reduction may be due to the actions of lycopene, quercetin or other flavonoids present in the leaf of $P$. guava. Lycopene may reduce blood pressure due to its high antioxidant properties as a result of having different structural formulas used in attacking many free radicals and oxidized cholesterols. Review by [20] on efficacy and mechanisms of quercetin in treatment of hypertension, shown vasorelaxation of isolated aortas of rats, by inhibiting the action of ET-1 at the gene transcription level, and promoted the production and action of nitric oxide on endothelium cells. As investigated by [16], Parinari curatellifolia locally is used in treating hypertension in dose dependently by activating nitric oxide production. Another study by [21] showed that on bioavailability of dietary polyphenols and the cardiovascular diseases, quercetin improved endothelial functions through inhibiting endothelial endothelin-1 (ET-1) and promoting nitric oxide. Since endothelium-dependent vasorelaxation and proper endothelial function is highly dependent on the production and bioavailability of nitric oxide.

\section{Conclusion}

Hypertension is elevation of blood pressure greater than or equal to $140 / 90 \mathrm{~mm} \mathrm{Hg}$. It is worldwide health and economic problem affects many peoples. Hypertension is worldwide risk factor for cardiovascular diseases. There are many drugs that used to treat hypertension. But all of these drugs have side effects. In order to minimize these side effects, many peoples have been using many different types of medicinal plants that can protect different types of diseases worldwide. These medicinal plants are cheaper, easy to accesses. $P$. guava is one of the most popular medicinal plant worldwide. This study was designed to detect the effect of ethanol extract of $P$. guava leaf on blood pressure of normotensive guinea pigs. In order to evaluate it invasive method was applied. As indicated blood pressure of normal guinea pigs was significantly reduced when treated with $P$. guava leaf extract in dose dependent manner. This is may be due to having of different by phytochemical compounds. 


\section{References}

[1] Sima Ataollahi Eshkoor, Tengku Aizan Hamid, Suzana Shahar, Chee Kyun Ng and Chan Yoke Mun (2016). Factors Affecting Hypertension among the Malaysian Elderly J. Cardiovasc. Dev. Dis., 3 (8): 1-10.

[2] Dominiczak Anna F., Kuo Denise R. K., (2015). Hypertension update. 65: 3-4. Journal of American Heart Association; 65: 3-4.

[3] Guwatudde D., Mutungi G., Wesonga R., Kajjura R., Kasule H., Muwonge J., Ssenono V., Bahendeka Silver K. (2015). The Epidemiology of Hypertension in Uganda: Findings from the National Non-Communicable Diseases Risk Factor Survey.

[4] American Heart Association (AHA). (2016). Scientific Sessions.

[5] Gorsane I., Mahfoudhi M., Younsi F., Helal I., Abdallah Taieb B. (2015). Prevalence and Risk Factors of Hypertension in Hemodialysis. Journal of Nephrology; 5: 54-60.

[6] Jellinger S., Smith A., Mehta E., Ganda O., Handelsman Y., Rodbard W., Shepherd D., Seibel A. (2012) the American Association for Clinical and Endocrinologists (AACE) guidelines for Management of Dyslipidemia and Prevention of Atherosclerosis. AACE lipid and Atherosclerosis guidelines. Endocrine Pract (18), pp 25-38.

[7] BCGuidelines.ca: Hypertension Diagnosis and Management Revised in 2016.

[8] Nandhini S., (2014). Essential Hypertension -A Review Article. J Pharm. Sci. and Res.; 6 (9), 305-307.

[9] Yao Lu, Minggen Lu, Haijiang Dai, Pinting Yang, Julie SmithGagen, Rujia Miao, Hua Zhong, Ruifang Chen, Xing Liu, Zhijun Huang, Hong Yuan (2015). Lifestyle and Risk of Hypertension: Follow-Up of a Young Pre-Hypertensive Cohort. Int. J. Med. Sci.; 12: 605-612.

[10] Twagirumukiza M., Bacquerb D., Kips J. G., de Backer G., Stichelec R. V. and Bortel M. V. (2011) Current and projected prevalence of arterial hypertension in sub-Saharan Africa by sex, age and habitat: an estimate from population studies. Journal of Hypertension; 29 (7).1243-125.

[11] Sharma, K., Vyawahare, S. and Ladhha A. (2010). Preclinical screening model for hypertension in rodents. Pharmacology Online; 3: 458-472.

[12] Thomford Nicholas E., Dzobo K, Chopera D, Wonkam A., Skelton M., Blackhurst D., Chirikure S. and Dandara C. (2015). Pharmacogenomics Implications of Using Herbal Medicinal Plants on African Populations in Health Transition. Journal Pharmaceuticals; 8: 637-663.

[13] Belayneh A., Asfa Z., Demissew S. and Bussa F. (2012). Medicinal plants potential and use by pastoral and agropastoral communities in Erer Valley of Babile Wereda, Eastern Ethiopia. Journal of Ethnobiology and Ethnomedicine; 8 (42).

[14] Tiwari Kapil Dev (2015). Hypertension and herbal plant for its treatment: a review. IJRPB 3 (5): 358.

[15] Moghadamtousi Z. S., Fadaeinasab M., Nikzad S., Mohan G., Ali M. H., 2 and Kadir A. H., (2015). A Review of Its Traditional Uses, Isolated Acetogenins and Biological Activities of Annona muricata (Annonaceae). Int. J. Mol. Sci.,

\section{6: $15625-15658$.}

[16] Dutta K. N., Chetia P., Lahkar S., Das Sumit, (2014). A comprehensive Review on Herbal Plants Used as Diuretics: Journal of Pharmaceutical, Chemical and Biological Sciences; 2 (1): $27-32$.

[17] Shruthi D., Roshan A., Timilsina S. and Sunita S.(2013). Review on the Medicinal Plant Psidium guajava Linn. (Myrtaceae). Journal of Drug Delivery and Therapeutics; 3 (2): $162-168$.

[18] Nunes Santos Gabrielle Marilia, Bernardino de Oliveira Amanda, Martins Duarte René, (2015). Use of medicinal plants by people with hypertension. Rev Rene; 6 (6): 775-783.

[19] Kingsley Eghianruwa I., Olayinka A. Oradea and Adebowale B. Saba (2016). Medicinal Plants Used for Meanagment of Hypertension in Nigeria. Annual Research and Review in Biology; 11 (3): 1-10.

[20] Larson A. J., Symons J. D. and Jalili T. (2010). Is quercetin a treatment for hypertension? A Review of Efficacy and Mechanisms. Pharmaceuticals; 3: 237-250.

[21] Shivashankara K. S., and Acharya S. N, (2010). Bioavailability of Dietary Polyphenols and the Cardiovascular Diseases. The Open Nutraceuticals Journal; 3: 227-241.

[22] Barbalho S. M., Farinazzi-Machado F. M. V., GoulartR. A., Brunnati A. C. S., Ottoboni A. M. B. and Nicolau C. C. T. (2012). Review on Psidium Guajava (Guava): A Plant of Multipurpose Medicinal Applications Med Aromat Plants; 1 (4): $1-6$

[23] Sandhar K., Kumar B., Prasher S., Tiwari P., Salhan M., Sharma P. (2011). A Review of Phytochemistry and Pharmacology of Flavonoids. International Pharmaceutical Science; 1: 25-35.

[24] Kumar A. (2012). Importance for life of Psidium guava. International Journal of Research in Pharmaceutical and Biomedical Sciences; 3 (1): 137-140.

[25] Mekoya. (2007). Hypotensive Effects of Aqueous Extract of Moringa stenopetala in both in vivoand in vitro Animal Models. Thesis for fulfillment of master degree in Physiology, Addis Ababa University; pp: 14-50.

[26] Shakeera B., Sujatha K, Sridharan G. and Manikandan R. (2013) Antihyperglycemic and antihyperlipidemic potentials of Psidium guajava in alloxan-induced diabetic rats. Asian $J$ Pharm Clin Res; 6 (2): 88-89.

[27] Mohd D. S., Khaizil E. Z and Norliza A. (2012). Screening on anti-proliferative activity of Psidium guajava leaves extract towards selected cancer celllines. Journal of US-China Medical Science; 9 (86): 30-37.

[28] Vanitha R. P., Sahana N, and Asna U. (2012). Anti-oxidant activity of Aegle, Marmelons and Psidium guava. Int. J. Med. Arom. Plants; 2 (1): 155-160.

[29] Ezekwesili O., Nkemdilim U. and Okeke U. (2010). Mechanism of antidiarrhoeal effect of ethanolic extract of Psidium guajava leaves. Biokemistry; 22 (2): 2-6.

[30] Fanta G., Anteneh B., Tsige G-M. (2010). Evaluation of Antimicrobial and Anti-inflammatory Activities Formulation Studies on the Leaf Extracts of Psidium gaujava L. Ethiop. Pharm. J. 28, 1. 
[31] Ekaluo U., Erem F., Omeje I., Ikpeme E., Ibiang Y. and Ekanem B. (2013). Is aqueous leaf extract of guava spermatotoxic in rat? Journal of Environmental Science, Toxicology and Food Technology; 3: 21-23.

[32] Sanda A., Grema A., Geidam A. and Bukar-KoloM. (2011). Pharmacological aspects of Psidium guajava. Journal of Pharmacology; 7: 316-324.
[33] Gilani H., Mandukhail S., Iqbal J., Yasinzai M., Aziz N., Khan A., Rehman N. (2010). Antispasmodic and vasodilator activities of Morinda citrifoliaroot extract are mediated through blockade of voltage dependent calcium channels. $B M C ; 10$ (2): 1472-6882. 